\title{
Diurnal trends in responses of blood plasma concentrations of glucose, insulin, and C-peptide following high- and low-fat meals and their relation to fat metabolism in healthy middle-aged volunteers
}

\author{
BY DAVID L. FRAPE ${ }^{1}$, NORMAN R. WILLIAMS ${ }^{2}$, A. J. SCRIVEN ${ }^{2}$, \\ CHRISTOPHER R. PALMER ${ }^{3}$, KATHRYN O'SULLIVAN $^{4}$ \\ AND REGINALD J. FLETCHER ${ }^{4 *}$ \\ ${ }^{1}$ N.S. Research, The Priory, Mildenhall, Suffolk, IP28 7EE \\ ${ }^{2}$ Pathology Department, Papworth Hospital, Cambridge CB3 8RE \\ ${ }^{3}$ University of Cambridge, Department of Community Medicine, Institute of Public Health, Robinson Way, \\ Cambridge CB2 2SR \\ ${ }^{4}$ The Kellogg Company of Great Britain Ltd, The Kellogg Building, Talbot Road, Manchester M16 OPU
}

(Received 29 December 1995 - Revised 20 June 1996 - Accepted 17 July 1996)

\begin{abstract}
An experiment was conducted in twelve healthy middle-aged volunteers, six of each sex, with a mean BMI of $27 \mathrm{~kg} / \mathrm{m}^{2}$ to detect differences between morning and afternoon in postprandial blood glucose, insulin and $\mathrm{C}$-peptide concentrations. These responses were measured following the consumption of isoenergetic meals that were high or low in fat content, at breakfast and at lunch. Over $4 \mathrm{~d}$ each subject received the high-carbohydrate ( $\mathrm{L}, 5.5 \mathrm{~g}$ mixed fat/meal) and moderately high-fat (M, $33 \mathrm{~g}$ mixed fat/meal) breakfasts and lunches, in three combinations (LL, MM, LM), or they fasted at breakfast time and received a moderately high-fat lunch (NM), in three Latin squares. Each evening a standard meal was given. Plasma glucose, insulin and $\mathbf{C}$-peptide responses were greater following $L$ than $M$ meals and within both $M M$ and $L L$ treatments insulin and C-peptide responses were greater following breakfast than following lunch. The incremental C-peptide response to a fatty lunch following a fast at breakfast time (NM) was similar to that to a fatty breakfast, but the incremental insulin response for the same comparison was marginally lower at lunch $(P=0 \cdot 06)$. The relationship of $C$-peptide and insulin concentrations was assessed. Plasma glucose response to a fatty lunch was increased by a fatty breakfast. The relationships of these metabolic events with fat metabolism are discussed.
\end{abstract}

Dietary fat: Dietary carbohydrate: Plasma: Insulin: Diurnal change

Insulin resistance is associated with raised fasting and postprandial plasma glucose and insulin concentrations. An almost twofold higher prevalence of hypertension, myocardial infarction, angina pectoris and congestive heart failure was found to be associated with impaired glucose tolerance in 644 men of 67 years of age (Ohlson et al. 1989). High-fat, low-carbohydrate diets have been used traditionally to induce insulin resistance in laboratory animals. Such diets, compared with isoenergetic high-carbohydrate diets, will induce resistance within $3 \mathrm{~d}$ in healthy volunteers (Sidery et al. 1990) and in rats (Smith, 1994).

Nevertheless it is not certain that dietary carbohydrate is to be preferred to fat in the prevention of disease related to insulin function. Elevated fasting concentrations of plasma triacylglycerol (TAG) tend to be associated with insulin resistance, an elevated 
postprandial TAG response, a decrease in plasma HDL-cholesterol concentration and atherogenesis (Baggio et al. 1980; Barbagallo et al. 1991; Frape \& Jones, 1995). Highcarbohydrate diets increase the postprandial insulin response and additions of fat to a meal may improve glycaemic index by delaying gastric emptying (Jones et al. 1984). In a study by Chen et al. (1993) the replacement of saturated fat by carbohydrate increased postprandial lipaemia, the extent of which was correlated with insulin response in patients with non-insulin-dependent diabetes (NIDDM) and replacement of fat with carbohydrate may increase fasting plasma TAG and lower plasma HDL-cholesterol concentrations (Smith, 1994). Previously, we (Frape \& Jones, 1995) observed much larger insulin responses to breakfast than to lunch and we questioned whether this was the result of an overnight fast and whether the source of the dietary energy affected the phenomenon. Van Cauter et al. (1992) also found a marginally greater maximum increment of serum insulin response to a morning meal than to an evening meal with a more rapid clearance of insulin in the evening, but there was a greater total area under the curve (AUC) of insulin secretory response to the evening meal.

The purpose of the present experiment was to determine whether: (1) there are differences between the acute postprandial responses to meals that have the same composition, or that are isoenergetic, but differ in fat content, when they are consumed at breakfast and at lunch and (2) whether such differences are related to the overnight fast, or to time of day. The meals were typical of traditional fatty and cereal breakfasts. The effects were measured on plasma glucose, insulin and C-peptide.

\section{MATERIALS AND METHODS}

Three groups of four healthy volunteers each (six males, six females) were tested over a $4 \mathrm{~d}$ period (Tuesday to Friday) in an experiment using a complete set of three orthogonal $4 \times 4$ Latin squares. These treatments consisted of meals of two compositions, providing similar amounts of metabolizable energy (ME): moderately high-fat, low-carbohydrate (M), or moderately low-fat, high-carbohydrate (L). An alternative treatment was no breakfast (N) and a $M$ lunch. The combinations of breakfasts and lunches are described in Table 1 and their composition is given in Table 2. The first subject in each square received meals at 08.30 hours and 13.00 hours. The remaining three subjects in each square, one at a time, received their meals at $5 \mathrm{~min}$ intervals, following the first subject, in the same sequence at breakfast and lunch.

Table 1. Energy values (MJ metabolizable energy) and timings of the meals consumed during the four different treatments

\begin{tabular}{lccc}
\hline \hline Treatment & Breakfast 08.30 hours* & Lunch 13.00 hours* & Dinner 18.15 hours \\
\hline LL & L, $\uparrow 2.08$ & L, 2.08 & 4.50 \\
MM & M, $\$ 2.17$ & M, 2.17 & 4.50 \\
NM & Fast \$ 0.0 & M, 2.17 & 4.50 \\
LM & L, 2.08 & M, 2.17 & 4.50 \\
\hline \hline
\end{tabular}

L, high-carbohydrate meal; $M$, moderately high-fat meal; $N$, no breakfast.

*Time at which the first subject started eating.

†Te $\mathrm{L}$ meal consisted of: pure orange juice $150 \mathrm{ml}$, cornflakes $86 \mathrm{~g}$, semi-skimmed milk $300 \mathrm{ml}$.

†The $\mathrm{M}$ meal consisted of: pure orange juice $150 \mathrm{ml}$, omelette (containing egg, ham, butter in a fried potato casing) $192.7 \mathrm{~g}$.

$\S$ Subjects received water $(150 \mathrm{ml})$ only. 
Table 2. Mean analytical compositions of the high-carbohydrate, cereal meal $(L)$ and the moderately high-fat omelette meal $(M)$

\begin{tabular}{|c|c|c|}
\hline & $\begin{array}{c}\text { Cereal, } \\
\text { L }\end{array}$ & $\begin{array}{c}\text { Omelette, } \\
\mathbf{M}\end{array}$ \\
\hline Metabolizable energy* (MJ) & 2.08 & 2.17 \\
\hline Fat (g) & 5.4 & 32.9 \\
\hline Saturated fatty acids (g) & 3.0 & $16 \cdot 0$ \\
\hline Monounsaturated fatty acids (g) & 1.7 & 11.8 \\
\hline Polyunsaturated fatty acids (g) & 0.5 & 4.0 \\
\hline Protein (g) & 17.9 & 29.3 \\
\hline Energy from $\mathrm{CHO}(\%)$ & 74.7 & 20.7 \\
\hline Energy from fat (\%) & 10.9 & $57 \cdot 3$ \\
\hline Dietary fibre (g) calculated & 0.86 & 0.35 \\
\hline
\end{tabular}

CHO, carbohydrate.

*Calculated from the measured protein, fat, starch and sugar contents.

The eating times for meals were controlled with the purpose of achieving similar times within-subject for breakfast and lunch. Orange juice was given, except to the fasted subjects, and was consumed in $30 \mathrm{~s}$ before the remainder of each meal. The fasted subjects received $150 \mathrm{ml}$ water at breakfast time. Both breakfasts and lunches were consumed in an average of $10 \mathrm{~min}$. These meals were followed by a constant evening meal at 18.15 hours of beefburger, three vegetables, yoghurt, and weak coffee, after which there were no postprandial measurements. A soft drink, half a pint of beer, or equivalent, was permitted between 19.00 hours and 20.00 hours daily. No other stimulating drink, or tobacco, was permitted during the course of the study. All subjects received $150 \mathrm{ml}$ carbonated water $2 \mathrm{~h}$ 5 min following the commencement of both breakfast and lunch.

The composition of the meals was determined by chemical analysis after preparation for eating. The fatty acid compositions of the fats in the $\mathbf{M}$ and $\mathrm{L}$ meals were very similar, predominately dairy fat, demonstrated by analysis. The methods of food analysis were those used by Frape \& Jones (1995).

\section{Subjects}

The twelve Caucasian subjects were selected subsequent to a medical examination and clinical analysis of blood samples. Only those found to be healthy participated (Table 3 ). The selected subjects were medically re-examined within $1-5 \mathrm{~d}$ before the commencement of the study.

Table 3. Characteristics of the subjects

(Mean values and standard deviations)

\begin{tabular}{|c|c|c|c|c|}
\hline & \multicolumn{2}{|c|}{ Men $(n$ 6) } & \multicolumn{2}{|c|}{ Women (n 6) } \\
\hline & Mean & SD & Mean & SD \\
\hline $\begin{array}{l}\text { BMI }\left(\mathrm{kg} / \mathrm{m}^{2}\right) \\
\text { Age (years) } \\
\text { Weight }(\mathrm{kg}) \\
\text { Fasting plasma triacylglycerols }(\mathrm{mmol} / \mathrm{l}) \\
\text { Fasting plasma total cholesterol }(\mathrm{mmol} / \mathrm{l})\end{array}$ & $\begin{array}{l}26.0 \\
56.6 \\
80.9 \\
1.15 \\
6.4\end{array}$ & $\begin{array}{r}3.40 \\
6.31 \\
14.98 \\
0.37 \\
0.70\end{array}$ & $\begin{array}{c}27.4 \\
52.4 \\
72 \cdot 6 \\
1.19 \\
6.4\end{array}$ & $\begin{array}{r}4.53 \\
9.41 \\
12.73 \\
0.51 \\
0.58\end{array}$ \\
\hline
\end{tabular}


All subjects attended Papworth Hospital in the afternoon of the day before the commencement of the study and they received the standard evening meal at 18.15 hours. All were given similar supervised accommodation, local to the hospital, overnight and during subsequent nights before metabolic study days. No abnormal exercise was allowed, other than a gentle short walk to be taken sometime between $2 \mathrm{~h}$ and $3.5 \mathrm{~h}$ after the commencement of breakfast and lunch.

\section{Response measurements}

An indwelling antecubital vein cannula was fitted at 07.30-08.00 hours each day, Tuesday to Friday, and removed each evening. Blood samples $(10 \mathrm{ml})$ were taken each day with times labelled (1) to (9), at: 0 (1), 30 (2), 60 (3), 120 (4), and 265 (5) min after the start of breakfast, and $0(5), 30(6), 60(7), 120(8)$, and $265(9) \mathrm{min}$, after the start of lunch. The blood samples taken at time point (5) fulfilled the dual purpose of the last post-breakfast sample and the immediate pre-lunch sample.

On each occasion the subject was seated for $5 \mathrm{~min}$ before and during phlebotomy, the cannula was flushed with saline and the first sample discarded. Blood samples were treated with lithium heparin apart from those for general haematology which were treated with fluoride-EDTA. The initial processing of all blood samples occurred within $2 \mathrm{~h}$ of collection. Samples for haematology were held at $2-4^{\circ}$ and they were analysed on the day of collection. Where plasma analyses were not undertaken immediately samples were held at $-70^{\circ}$ until analysed. Each determinant for a replicate of samples was assayed in a single run, except for C-peptide which was assayed in two runs. The two assays of plasma Cpeptide concentration were conducted on balanced sub-groups of the blood plasma samples. Plasma C-peptide was measured by radioimmunoassay, using a Guildhay Cpeptide kit number G029 (Guildhay Ltd, Guildford, Surrey) and plasma insulin was measured by radioimmunoassay using a Pharmacia insulin kit (Kabi Pharmacia Diagnostics AB, Uppsala, Sweden). Plasma glucose was measured by the glucose oxidase (EC 1.1.3.4) method and the $\mathrm{O}_{2}$ liberated was measured with an Analox $\mathrm{O}_{2}$ electrode. The determined intra-assay $\mathrm{CV}$ for the glucose determination was $1.3 \%$.

\section{Statistical methods}

Responses for all repeated measurement variables were summarized at individual subject level by area under the curve (AUC), calculated by applying the trapezium rule for time points 1-5 and 5-9 for morning and afternoon respectively (Altman, 1991). The baseline for this calculation was zero. Incremental AUC (IAUC) were also calculated for which the baselines were time 1 for time points $1-5$ and time 5 for time points 5-9. Variables not normally distributed were log-transformed towards normality. Multiple regression analyses, including subject as a factor, allowed comparisons to be made between diets and time of day within subject. The responses $0-60 \mathrm{~min}$ postprandially for insulin and Cpeptide and their relationship were assessed by $t$ test and graphically. Spearman's rank correlation was employed to assess associations. Paired $t$ tests were used for within-subject comparisons on approximately normally distributed variables. All computations were carried out with SPSS for Windows (Statistical Package for the Social Sciences version 6.0, 1993) software (SPSS (UK) Ltd). 


\section{Ethical considerations}

The protocol for the experiment was approved by the Huntingdon Area Medical Ethics Committee and all subjects gave informed written consent to participate.

\section{RESULTS}

\section{Plasma insulin and insulin : glucose}

The responses, measured as the geometric means of the AUC and IAUC for plasma insulin and insulin : glucose ratio are given in Table 4. The baseline for AUC was zero for morning and afternoon, whereas for IAUC the baselines were the pre-meal values for morning (time 1) and for afternoon (time 5). The results indicated larger values for the $L$ meals than for the $\mathrm{M}$ meals, in both the morning and afternoon, measured both as AUC and IAUC for insulin and as AUC and IAUC of the insulin: glucose ratio $(P<0.001)$. Moreover, the responses to breakfast were larger than those to lunch within the LL and MM treatments, measured as AUC and IAUC values for insulin (Fig. 1) and as insulin: glucose ratio $(P<0.05)$, with the exception of the comparison MM morning $v$. MM afternoon for IAUC insulin: glucose ratio, where the difference was not significant, $P>0.05$ (Table 5).

Table 4. Areas under the curve (AUC) and incremental AUC (IAUC) for insulin, glucose and the insulin: glucose ratio measured after breakfast (am) and lunch (pm) meals in subjects consuming two consecutive meals of the same or different composition*

(Mean values with their standard errors for twelve subjects)

\begin{tabular}{|c|c|c|c|c|c|}
\hline & \multirow[b]{2}{*}{ Treatment } & \multicolumn{2}{|c|}{ am } & \multicolumn{2}{|c|}{$\mathrm{pm}$} \\
\hline & & Mean & SE & Mean & SE \\
\hline İnsulin, AUC & LL & 9.42 & 0.12 & 9.24 & 0.08 \\
\hline \multirow[t]{3}{*}{$\ln (\mu \mathrm{U} / \mathrm{ml} . \mathrm{h})$} & MM & 8.53 & 0.09 & 8.41 & $0 \cdot 10$ \\
\hline & NM & 7.58 & 0.08 & 8.34 & 0.08 \\
\hline & LM & 9.42 & 0.11 & 8.38 & 0.09 \\
\hline Insulin, IAUC & $\mathbf{L L}$ & 9.33 & 0.12 & 9.02 & 0.08 \\
\hline \multirow[t]{3}{*}{$\ln \left((\mu \mathrm{U} / \mathrm{ml} . \mathrm{h})+10^{3}\right)$} & $\mathbf{M M}$ & $8 \cdot 30$ & 0.08 & $8 \cdot 04$ & 0.08 \\
\hline & NM & 6.81 & 0.09 & 8.20 & 0.07 \\
\hline & LM & 9.28 & 0.09 & 7.62 & 0.11 \\
\hline Glucose, AUC & LL & $26 \cdot 30$ & 1.27 & 26.58 & 0.82 \\
\hline \multirow[t]{3}{*}{ (mmol/l.h) } & $\mathbf{M M}$ & 22.23 & 0.58 & 23.92 & 0.52 \\
\hline & NM & 20.92 & 0.55 & 22.95 & 0.57 \\
\hline & LM & 26.97 & $1 \cdot 10$ & 22.38 & 0.43 \\
\hline Insulin : glucose, AUC & LL & 7.59 & 0.10 & 7.40 & 0.09 \\
\hline \multirow[t]{3}{*}{$\ln (\mathrm{mU} / \mathrm{mmol} . \mathrm{h})$} & $\overline{\mathbf{M M}}$ & 6.89 & 0.08 & 6.72 & 0.10 \\
\hline & NM & 6.05 & 0.08 & 6.68 & 0.09 \\
\hline & $\mathbf{L M}$ & 7.56 & 0.09 & 6.75 & 0.09 \\
\hline Insulin : glucose, IAUC† & LL & 7.13 & 0.11 & 6.79 & $0 \cdot 10$ \\
\hline \multirow[t]{3}{*}{$\ln (\mathrm{mU} / \mathrm{mmol} \mathrm{h})$} & MM & 5.82 & 0.24 & 5.81 & 0.12 \\
\hline & NM & $5 \cdot 18$ & $0 \cdot 10$ & 5.94 & $0 \cdot 15$ \\
\hline & LM & 7.07 & 0.11 & 5.58 & 0.14 \\
\hline
\end{tabular}

LL, high-carbohydrate breakfast and lunch; MM, moderately high-fat breakfast and lunch; NM, no breakfast, moderately high-fat lunch; LM, high-carbohydrate breakfast, moderately high-fat lunch.

*For details of meals and procedures, see Tables 1 and 2 and pp. 524-526.

$\dagger$ The IAUC insulin : glucose $=\ln (($ postmeal(insulin : glucose $) \times t)-($ pre-meal(insulin : glucose $) \times t))$, where $t=4.42 \mathrm{~h}$. 


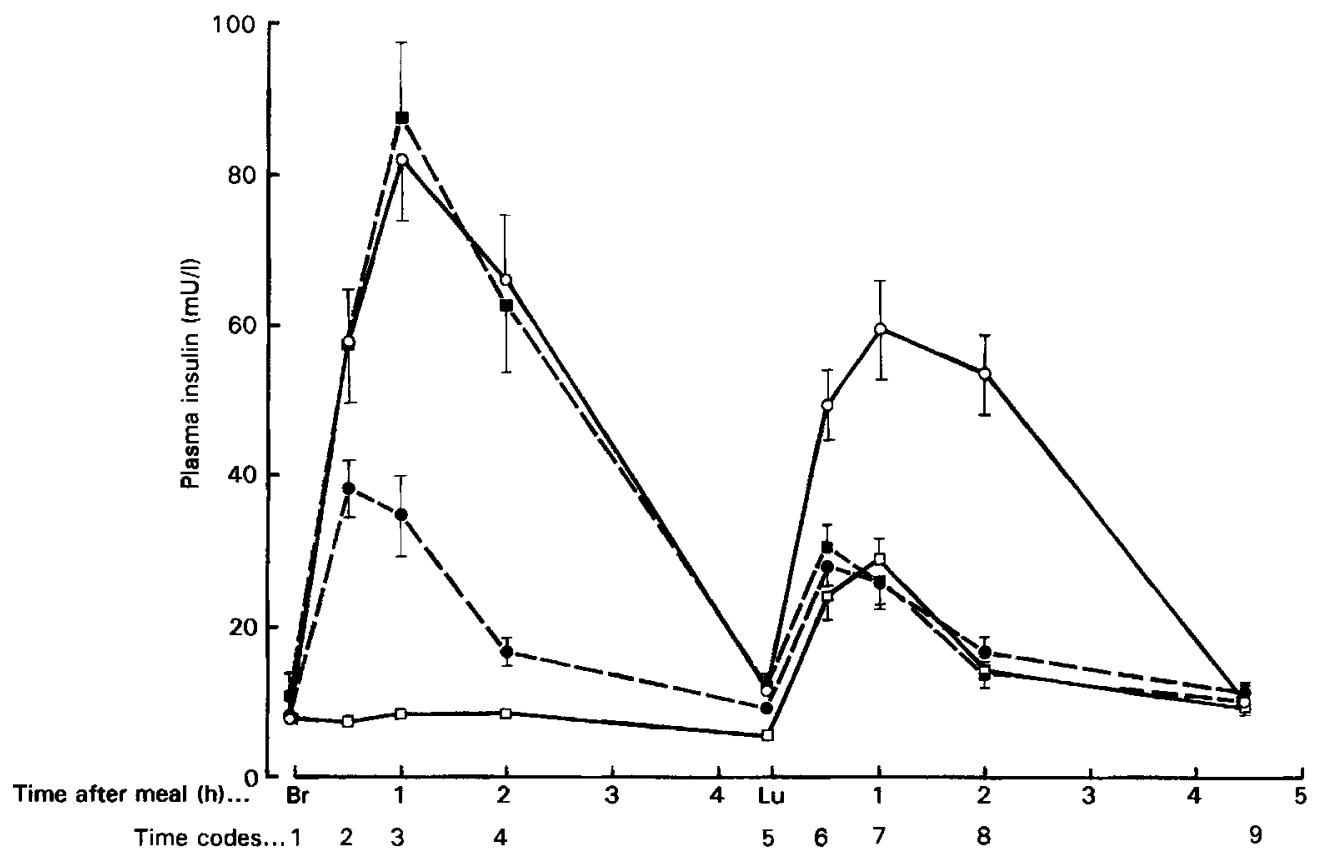

Fig. 1. Plasma insulin concentrations measured over a period of $4 \mathrm{~h} 25 \mathrm{~min}$ from the start of breakfast (Br) and lunch (Lu) meals in subjects consuming two consecutive meals of the same or different composition. (O), High-carbohydrate breakfast and lunch, LL; (O), moderately high-fat breakfast and lunch, MM; $(\square)$, no breakfast, moderately high-fat lunch, NM; (W), high-carbohydrate breakfast, moderately high-fat lunch, LM. Values are means for twelve subjects, with their standard errors represented by vertical bars. The area under the curve for insulin after breakfast was significantly greater than that after lunch for treatments $\mathrm{LL}, \mathrm{MM}$ and $\mathrm{LM}, P<0.03$.

For the first meal of the day AUC insulin and AUC insulin : glucose ratio were greater for MM (morning) than for NM (afternoon) $(P=0.0001)$, although when adjustment was made for pre-meal values the IAUC insulin and IAUC insulin: glucose ratio differences between MM in the morning and NM in the afternoon were not significant, $P>0.05$. Moreover, in the afternoon the IAUC for insulin was greater for NM than for MM $(P=0.01)$ so that the insulin response to the first meal of the day, when taken in the afternoon, was not significantly different from that to the first meal taken in the morning.

\section{Plasma C-peptide}

Plasma C-peptide concentrations following fatty meals approached fasting levels by $4.42 \mathrm{~h}$ from the commencement of each meal. On the other hand, the maximum increment of plasma C-peptide over the first hour after a meal is considered to indicate insulin secretory response to that meal. The values in Table 6 and the increments in Fig. 2 indicate a striking difference between the morning and the afternoon in the responses over that first hour after a meal, i.e. times $(3-1) v$. $(7-5)$ for both treatments $L L$ and $M M(P=0.0001$ and $\mathbf{P}=0.005$ respectively). Within the fatty meals the $C$-peptide response over the first postprandial hour to treatment NM in the afternoon was significantly different from that to $\mathrm{MM}$ in the afternoon $(P=0.002)$, but not significantly different from that to $\mathrm{MM}$ in the morning $(P=0.70$; Fig. 2$)$, owing in large part to a lower pre-lunch value for the NM 





Table 6. Plasma $C$-peptide concentrations $(\mu g / l)$ at various times during the day in subjects consuming consecutive breakfast and lunch meals of the same or different compositions*

(Mean values with their standard errors for twelve subjects)

\begin{tabular}{|c|c|c|c|c|c|c|c|c|}
\hline \multirow{2}{*}{$\begin{array}{l}\text { Time } \\
\text { (hours) }\end{array}$} & \multicolumn{2}{|c|}{ LL } & \multicolumn{2}{|c|}{$\mathbf{M M}$} & \multicolumn{2}{|c|}{$\mathbf{N M}$} & \multicolumn{2}{|c|}{ LM } \\
\hline & Mean & SE & Mean & SE & Mean & SE & Mean & SE \\
\hline 08.30 & 2.22 & 0.15 & $2 \cdot 28$ & 0.21 & ND & & ND & \\
\hline 09.30 & 10.63 & 0.70 & 6.04 & 0.46 & ND & & ND & \\
\hline 13.00 & 4.09 & 0.50 & 2.45 & 0.23 & 1.62 & 0.12 & 3.49 & 0.33 \\
\hline 14.00 & 7.65 & 0.74 & $5 \cdot 26$ & 0.36 & 5.69 & 0.28 & $5 \cdot 70$ & 0.41 \\
\hline 17.30 & 3.66 & 0.29 & 3.06 & 0.32 & 3.08 & 0.35 & ND & \\
\hline
\end{tabular}

LL, high-carbohydrate breakfast and lunch; MM, moderately high-fat breakfast and lunch; NM, no breakfast, moderately high-fat lunch; LM, high-carbohydrate breakfast, moderately high-fat lunch; ND, not determined.

*For details of meals and procedures, see Tables 1 and 2 and pp. 524-526.

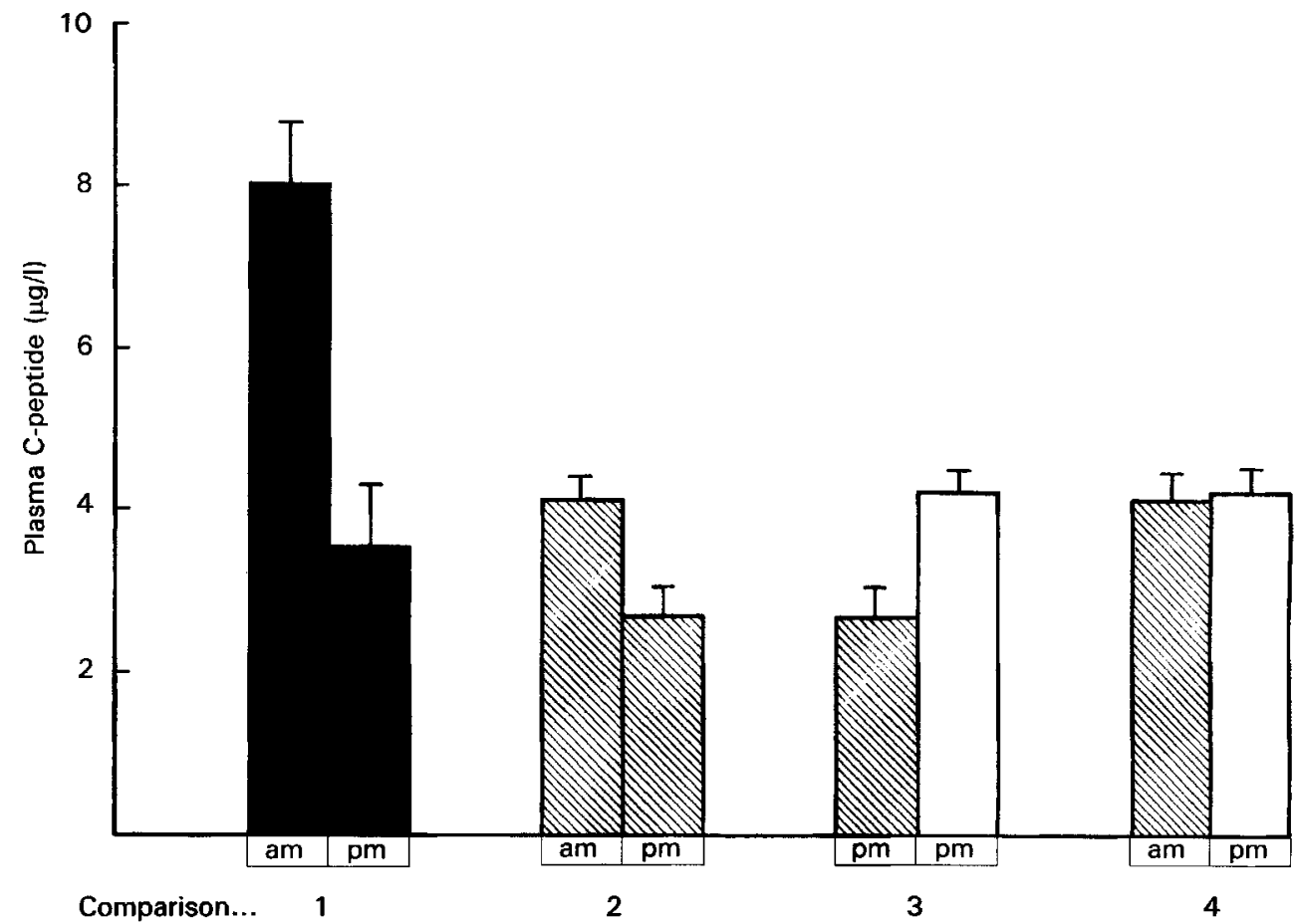

Fig. 2. Paired comparisons between increments in plasma C-peptide concentration measured from 0 to $1 \mathrm{~h}$ after the start of breakfast (am) and lunch (pm) meals, in subjects consuming two consecutive meals of the same or different composition. Values are means for eight subjects, with their standard errors represented by vertical bars. Treatments were: LL, high-carbohydrate breakfast and lunch; MM, moderately high-fat breakfast and lunch; NM, no breakfast, moderately high-fat lunch. Comparison 1: $\mathrm{LL}$ am $>\mathrm{pm}, P=0.0001$; comparison 2: $\mathrm{MM}$ am $>\mathrm{pm}, P=0.005$; comparison 3: $\mathrm{MM}$ pm $<\mathrm{NM}$ pm, $P=0.002$; comparison 4: $\mathrm{MM}$ am $v$. NM pm, $P=0.70$.

treatment than for the MM treatment (Table 6). This outcome is similar to that for the insulin response.

The plasma response increments over $0 \mathrm{~h}$ to $1 \mathrm{~h}$ postprandially, after breakfast and after lunch, for insulin and the C-peptide were plotted within subject (Fig. 3). Within treatment $L L$ the response line from the greater morning value to the lesser afternoon value 
for each subject showed the same directional pattern and in all cases the co-ordinate for the $C$-peptide: insulin ratio in the morning was larger than that for the same ratio in the afternoon. A comparison of the differences between sampling times, $((3-1) v .(7-5))$, for this ratio, i.e. the response from $0 \mathrm{~h}$ to $1 \mathrm{~h}$ postprandially for morning $v$. afternoon in treatment $\mathrm{LL}$, yielded a value of 8.3 (SE 3.8) $\mu \mathrm{g} / \mathrm{mU}, P=0.07$. These observations indicate a lower afternoon extraction rate following a much lower afternoon secretion rate for the LL treatment. The responses within the other treatments, all of which contained fatty meals, showed no consistent trend (Fig. 3).

\section{Plasma glucose}

There was no significant difference between the morning and afternoon pre-meal values and therefore only AUC values were assessed. The plasma glucose AUC response was higher for LL than for MM during both the morning and the afternoon $(P=0.0001)$ and it was higher for MM after lunch than for either MM after breakfast $(P=0.004)$, or for LM after lunch $(P=0.03)$ (Tables 4 and 5, Fig. 4). Moreover, the IAUC for the insulin : glucose ratio for MM after lunch was greater than that for $\mathrm{LM}$ after lunch $(P=0.05)$. There was, on the other hand, no significant difference between morning and afternoon values for treatment LL. The treatment effect for fatty meals was significant $(P=0.04)$.

\section{DISCUSSION}

In the present experiment greater plasma insulin and C-peptide responses occurred (1) following breakfast than following lunch and (2) to a high-carbohydrate meal than to a fatty meal. The plasma glucose response to a fatty lunch was increased by a fatty breakfast, and this was associated with a considerable elevation in plasma non-esterified fatty acids (NEFA) in the afternoon in this experiment (Frape et al. 1994). Increases in plasma NEFA concentration, turnover and oxidation rates, induced by a high fat diet, impair dietary glucose oxidation through the glucose-NEFA cycle (Randle et al. 1963) and increase hepatic gluconeogenesis. An increase in plasma NEFA concentration also impairs the action of key proteins in insulin binding and signal propagation in isolated hepatocytes by mechanisms related to their oxidation. NEFA concentrations, within the range of those detected in plasma derived from treatment MM after lunch (Frape et al. 1994), in contact with isolated hepatocytes are able to cause these effects (Svedberg et al. 1990, 1991), expressed as insulin resistance; but a high-carbohydrate meal, yielding glucose, inhibits NEFA release into the circulation. The interpretation and implications of these effects, and the diurnal changes in insulin response, are discussed.

The high-carbohydrate meal led to considerably greater plasma glucose and insulin responses, compared with the fatty meal of the same energy content, at breakfast and at lunch, in healthy middle-aged volunteers. These effects accorded with expectation; but plasma insulin and $\mathrm{C}$-peptide concentrations at $1 \mathrm{~h}$ postprandially in response to both the moderately high- and low-fat meals were greater in the morning than in the afternoon. Our observations indicated that insulin secretion is greater to a given energy allowance following a morning breakfast than it is following the subsequent lunch in middle-aged, slightly obese, subjects.

The C-peptide incremental response to NM after lunch was very similar to that for MM after breakfast (Fig. 2) and the difference between these treatment meals, measured as the IAUC for insulin, was not significant, $P>0.05$ (Table 5). However, the AUC insulin response to $\mathrm{MM}$ after breakfast was considerably greater than the comparable insulin 

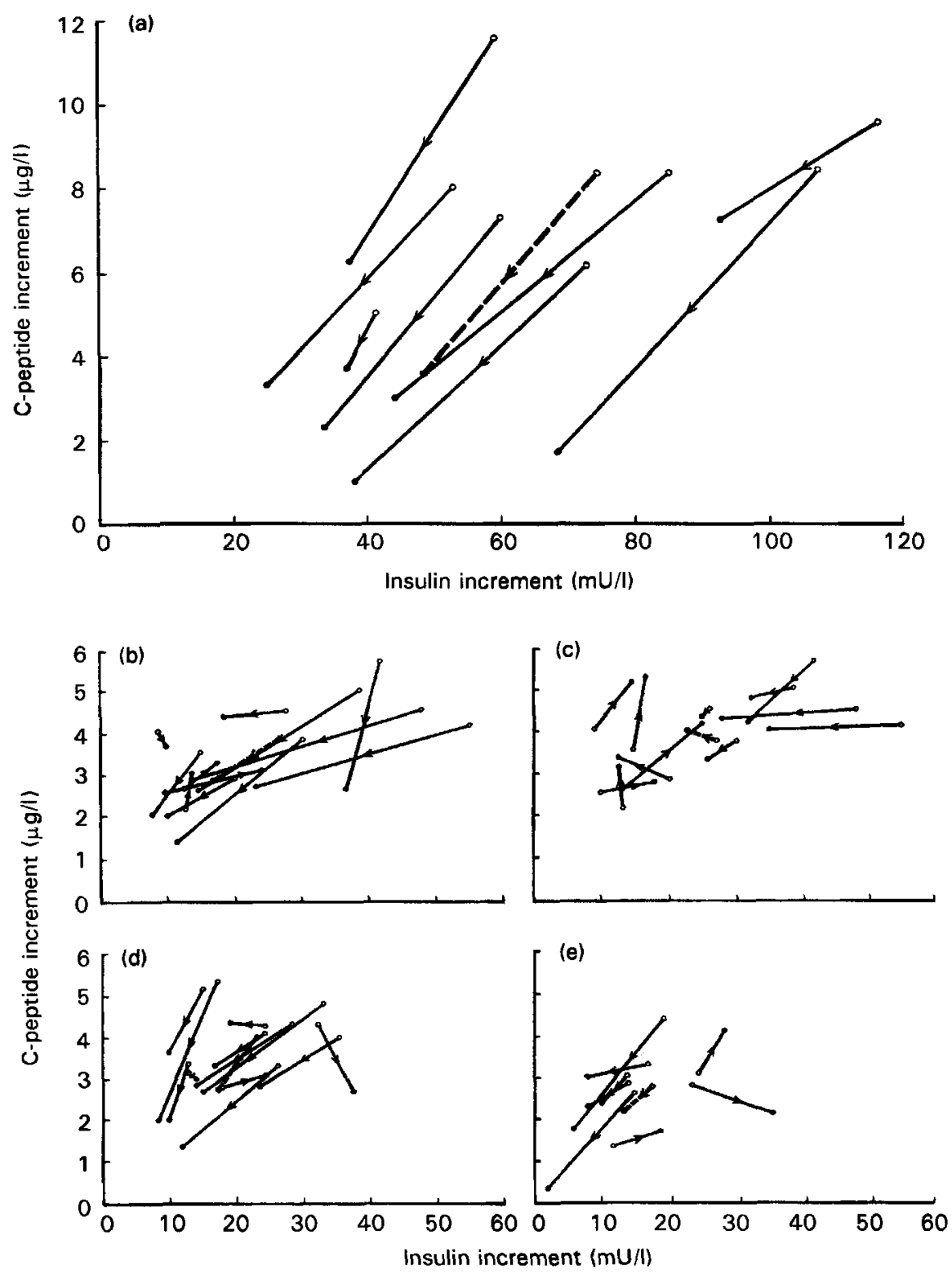

Fig. 3. Within-subject increments (measured from 0 to $1 \mathrm{~h}$ after the start of breakfast (am) and lunch (pm) meals) of plasma C-peptide $v$. plasma insulin, in subjects consuming two consecutive meals of the same or different composition. Each line joins the coordinate of one pair of responses to that of the other. Treatments were: LL, high-carbohydrate breakfast and lunch; MM, moderately high-fat breakfast and lunch; NM, no breakfast, moderately high-fat lunch; LM, high-carbohydrate breakfast, moderately high-fat lunch. Responses joined by each line (with standard errors of Cpeptide and insulin measurements respectively) are: (a) LL am (SE 0.67, 7.6) $\rightarrow$ LL pm (SE 0.75, 6.2); (b) MM am (SE $0.31,4.6) \rightarrow \mathrm{MM}$ pm (SE 0.23, 2.3); (c) MM am (SE 0.31, 4.6) $\rightarrow$ NM pm (SE 0.23, 2.3); (d) NM pm (SE 0.23, $2.3) \rightarrow$ MM pm (SE 0.23, 2.3); (e) MM pm (SE 0.23, 2.3) $\rightarrow$ LM pm (SE 0.39, 2.9). ( $\rightarrow$ ) Mean responses joined by discontinuous lines and the SE values are given against coordinates for $L L$. 


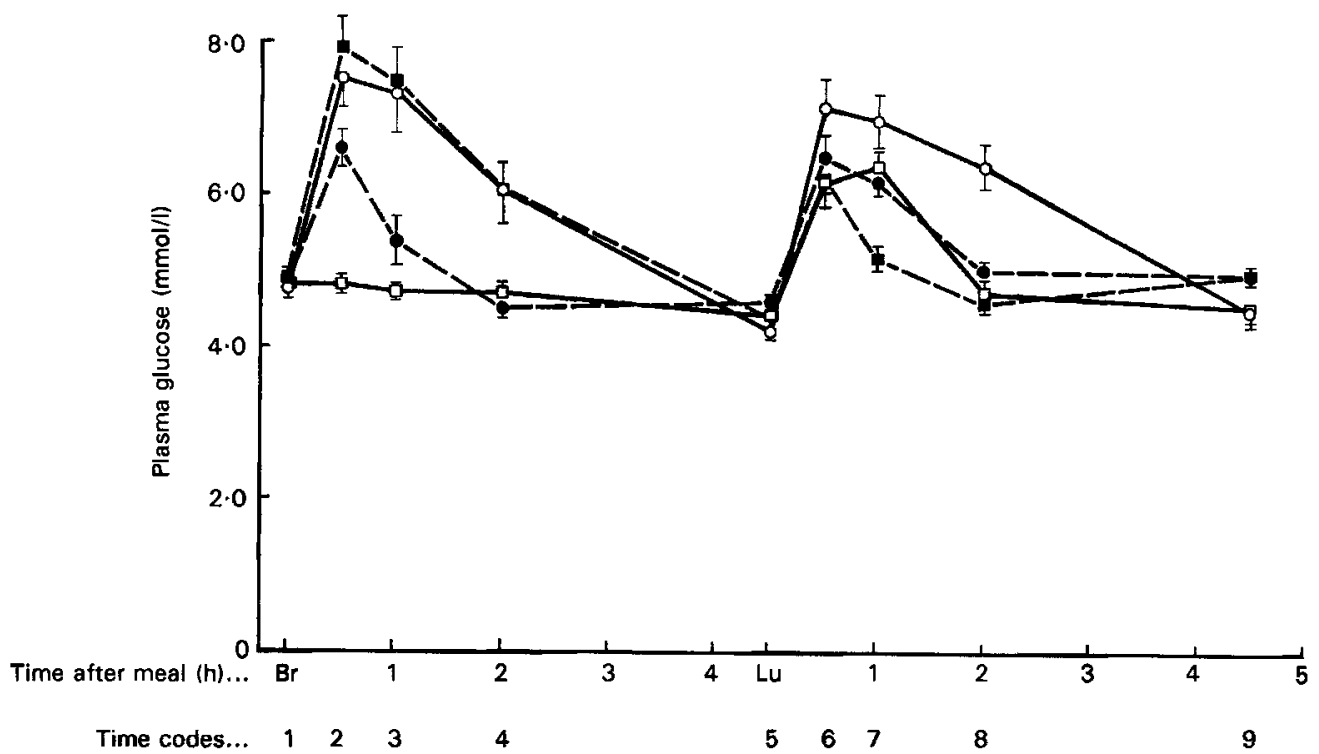

Fig. 4. Plasma glucose concentrations measured over a period of $4 \mathrm{~h} 25 \mathrm{~min}$ from the start of breakfast (Br) and lunch (Lu) meals in subjects consuming two consecutive meals of different composition. $(\mathrm{O})$, High-carbohydrate breakfast and lunch, LL; (O), moderately high-fat breakfast and lunch, MM; ( $\square$ ), no breakfast, moderately high-fat lunch, NM; (ם), high-carbohydrate breakfast, moderately high-fat lunch, LM. Values are means for twelve subjects, with their standard errors represented by vertical bars. The area under the curve for glucose after breakfast was significantly smaller than that after lunch for treatment MM, $P=0.004$; and that for MM after lunch was greater than that for $L M$ after lunch, $P=0.03$.

response to $\mathrm{NM}$ after lunch $(P=0.001)$. This difference in outcome between AUC and IAUC values reflected the combined effects of differences between morning and afternoon in circulating concentrations of insulin and C-peptide and the slightly lower concentrations pre-lunch in NM than pre-breakfast in MM. The raised plasma insulin concentrations following breakfast are concluded to be largely a response to a meal after an overnight fast and factors associated with differences between night and day in sleep, activity etc. Van Cauter et al. (1992) also found that glucose and insulin responses to mixed meals were profoundly modulated by circadian rhythmicity and concluded that the diurnal variation in meal tolerance was at least partly mediated by circulating cortisol concentrations. They found that the glucose response to a meal at 20.00 hours was greater than that to one at 08.00 hours and the AUC insulin secretory response to the evening meal was $25-50 \%$ greater than that to the morning meal. This diumal increase in AUC insulin response to meals was correlated with a decline in pre-meal serum cortisol concentration. They found that both the pre-meal plasma level of, and the post-meal increment in, plasma cortisol were greater to a meal at 08.00 hours than to meals at either midday or at 20.00 hours. As cortisol increases the rate of gluconeogenesis and suppresses cellular glucose utilization one may have expected a response more in accord with our observations, both in the present experiment and those reported previously (Frape \& Jones, 1995), that is an increased requirement for insulin in response to a morning meal, rather than in response to meals later in the day.

The AUC of the plasma glucose response to treatment $\mathrm{MM}$ after lunch was higher than it was for the same treatment after breakfast $(P=0.004$; Table 5), but in treatment LL there was no significant difference between morning and afternoon glucose responses. This 
difference is likely to have been caused by the treatment differences found in circulating NEFA concentrations in the afternoon (Frape et al. 1994). The reduction in the afternoon plasma NEFA concentration, induced by replacing the fatty breakfast by cereal (LM afternoon $v$. MM afternoon) may have caused the relatively low afternoon IAUC for insulin, AUC for glucose and IAUC for insulin : glucose ratio responses in treatment LM ( $P=0.008, P=0.03$ and $P=0.05$ respectively, Table 5). These differences may be the result of a blocking of glucose oxidation by fatty meals that causes a release of NEFA into the blood (Ferrannini et al. 1983). The high levels of circulating NEFA in treatment MM after lunch could have depended on increased tissue sensitivity to insulin at that time of day, and the consumption of the fatty breakfast, both stimulating the activity of adipose tissue lipoprotein lipase ( $E C$ 3.1.1.34, LPL). A difference, in this respect, between treatment MM afternoon, on the one hand, and treatments NM and LM (both afternoon) on the other, would then account for the considerably lower circulating levels of TAG in the final daily blood samples (sample time 9) of treatment MM in the afternoon compared with LM in the afternoon (Frape et al. 1994).

Van Cauter et al. (1991) found a strong positive correlation between the absolute increase in plasma glucose concentration in response to glucose infusion during nocturnal sleep and the amount of growth hormone (GH) secreted between 22.00 hours and 02.00 hours. GH tends to inhibit cellular glucose utilization and the GH rhythm may have controlled the circadian variation in the AUC for plasma glucose, noted in the response to meals at 08.00 and 20.00 hours, where the AUC for glucose was larger in the evening (Van Cauter et al. 1992). Although we found a somewhat similar difference in plasma glucose between morning and afternoon in treatment $\mathrm{MM}$, no such difference was noted in treatment LL. We have suggested that the morning $v$. afternoon difference in the AUC for glucose for treatment MM could be explained by the time difference in plasma NEFA concentration. The divergence between our experiment and those of Van Cauter $e t$ al. (1992) may have resulted in part from the difference in the time of the last daily test meal, i.e. 13.00 hours $v .20 .00$ hours and a difference in circadian pattern in endocrine secretions. The pattern in the experiment of Van Cauter et al. (1992) may have been influenced by the stress of wakening their subjects at 02.00 hours for $45 \mathrm{~min}$ and their use of subjects who were both younger and had a lower BMI. Plasma GH concentration in our subjects is likely to have been no more than half that of the younger and leaner subjects engaged by Van Cauter et al. (1991, 1992) (Guyton \& Hall, 1996). We speculate that an inhibition of glucose clearance by $\mathrm{GH}$ in the evening may initiate an inflated evening insulin response, whereas with older and fatter subjects an evening stimulus to insulin would be less marked and would not occur at lunchtime when circulating GH was at a low concentration.

\section{CONCLUSIONS}

High-carbohydrate meals led to considerably greater plasma glucose and insulin responses, compared with fatty meals of the same energy content, at breakfast and at lunch, in healthy middle-aged volunteers.

Insulin secretion was greater at breakfast than at lunch following the consumption of meals of the same composition and energy content, either high in fat, or high in carbohydrate. The difference in secretion appeared to be due mainly to the extension of the time interval between meals before the first daily meal, as the first daily meal taken at 13.00 hours yielded similar responses to the first meal at 08.30 hours. The time of the daily maxima and minima of plasma insulin and glucose responses to meals may depend partly on age and fatness of the individual. 
The consumption of a moderately low-fat cereal breakfast lowered the plasma glucose response to a moderately fatty lunch, compared with the effects of a moderately fatty breakfast preceding the fatty lunch. However, it was previously found that plasma fat clearance after the fatty lunch was delayed if a high-carbohydrate breakfast, rather than a fatty one, had been taken. Whether a lower plasma glucose response after lunch, or an earlier fat clearance after lunch is the more critical for long-term health remains to be determined. A delay in plasma fat clearance in the afternoon, associated with the cereal breakfast, may have contributed to the lower afternoon NEFA AUC. This lower AUC could have been causal in the concurrent decreased plasma glucose response.

The authors would like to acknowledge the assistance of Drs J. W. Foote, A. N. Howard, and L. Pandya. They are also grateful to Mrs J. West and Mr Christopher Marshall for technical assistance and to the volunteer subjects who participated in the studies.

\section{REFERENCES}

Altman, D. G. (1991). Practical Statistics for Medical Research. London: Chapman and Hall.

Baggio, G., Fellin, R., Baiocchi, M. R., Martini, S., Baldo, G., Manzato, E. \& Crepaldi, G. (1980). Relationship between triglyceride-rich lipoprotein (chylomicrons and VLDL) and HDL2 and HDL3 in the post-prandial phase in humans. Atherosclerosis 37, 271-276.

Barbagallo, C. M., Averna, M. R., Amato, S., Davi, G., Pagano, D., Noto, D. \& Notarbartolo, A. (1991). Lipid and apoprotein behaviour after an oral fat load in hypertriglyceridaemia. Diabetes Metabolism 17, 512-519.

Chen, Y.-D. I., Swami, S., Skowronski, R., Coulston, A. \& Reaven, G. M. (1993). Differences in postprandial lipemia between patients with normal glucose tolerance and noninsulin-dependent diabetes mellitus. Journal of Clinical Endocrinology and Metabolism 76, 172-177.

Ferrannini, E., Barrett, E. J., Bevilacqua, S. \& DeFronzo, R. A. (1983). Effect of fatty acids on glucose production and utilization in man. Journal of Clinical Investigation 72, 1737-1747.

Frape, D. L. \& Jones, A. M. (1995). Chronic and postprandial responses of plasma insulin, glucose and lipids in volunteers given dietary fibre supplements. British Journal of Nutrition, 73, 733-751.

Frape, D. L., Williams, N. R., Pickersgill, J., Murrills, R., Palmer, C. \& Fletcher, R. J. (1994). The postprandial response to high-fat, low-carbohydrate and low-fat, high-carbohydrate meals providing the same amounts of energy in subjects at risk of heart disease. Proceedings of the Nutrition Society, 53, 221A.

Guyton, A. C. \& Hall, J. E. (1996). Textbook of Medical Physiology, 9th ed., p. 942. Philadelphia: W.B. Saunders Company.

Jones, D. B., Patel, S., Slaughter, P., Carter, R. D., Mann, J. I. \& Hockaday, T. D. (1984). A comparison of isocaloric high carbohydrate and high fat test meals in diabetics. Postgraduate Medical Journal 60, $129-131$.

Ohlson, L. O., Bjuro, T., Larsson, B., Eriksson, H., Svardsudd, D., Welin, L. \& Wilhelmsen, L. (1989). A crosssectional analysis of glucose tolerance and cardiovascular disease in 67-year-old men. Diabetic Medicine 6 , $112-120$.

Randle, P. J., Garland, P. B., Hales, C. N. \& Newsholme, E. A. (1963). The glucose fatty-acid cycle. Its role in insulin sensitivity and the metabolic disturbances of diabetes mellitus. Lancet 1, 785-789.

Sidery, M. B., Gallen, I. W. \& MacDonald, I. A. (1990). The initial physiological responses to glucose ingestion in normal subjects are modified by a $3 \mathrm{~d}$ high-fat diet. British Journal of Nutrition 64, 705-713.

Smith, U. (1994). Carbohydrates, fat, and insulin action. American Journal of Clinical Nutrition 59, Suppl., 686S-689S.

Svedberg, J., Björntorp, P., Lönnroth, P. \& Smith, U. (1991). Prevention of inhibitory effect of free fatty acids on insulin binding and action in isolated rat hepatocytes by Etomoxir. Diabetes 40, 783-786.

Svedberg, J., Björntorp, P., Smith, U. \& Lönnroth, P. (1990). Free-fatty acid inhibition of insulin binding, degradation, and action in isolated rat hepatocytes. Diabetes 39, 570-574.

Van Cauter, E., Blackman, J. D., Roland, D., Spire, J.-P., Refetoff, S. \& Polonsky, K. S. (1991). Modulation of glucose regulation and insulin secretion by circadian rhythmicity and sleep. Journal of Clinical Investigation 88, 934-942.

Van Cauter, E., Shapiro, E. T., Tillil, H. \& Polonsky, K. S. (1992). Circadian modulation of glucose and insulin responses to meals: relationship to cortisol rhythm. American Journal of Physiology 262, E467-E475. 